\title{
Disparities in access to food and chronic obstructive pulmonary disease (COPD)-related outcomes: a cross-sectional analysis
}

\author{
Eric Moughames ${ }^{1 *}$, Han Woo², Panagis Galiatsatos², Karina Romero-Rivero², Sarath Raju², Vickram Tejwani \\ Eric A. Hoffman ${ }^{3}$, Alejandro P. Comellas ${ }^{3}$, Victor E. Ortega ${ }^{4}$, Trisha Parekh ${ }^{5}$, Jerry A. Krishnan 6 , \\ Michael B. Drummond ${ }^{7}$, David Couper ${ }^{8}$, Russell G. Buhr ${ }^{9}$, Robert Paine ${ }^{10}$, Joel D. Kaufman ${ }^{11}$, Laura M. Paulin ${ }^{12}$, \\ Nirupama Putcha ${ }^{2}$ and Nadia N. Hansel ${ }^{2}$
}

\begin{abstract}
Background: Millions of Americans are living in food deserts in the United States, however the role of the local food environment on COPD has not been studied. The aim of this study is to determine the association between food deserts and COPD-related outcomes.

Method: In this cross-sectional analysis we linked data collected from SPIROMICS (SubPopulations and InteRmediate Outcome Measures in COPD Study) between 2010 and 2015 and food desert data, defined as an underserved area that lacks access to affordable healthy foods, from the Food Access Research Atlas. COPD outcomes include percentage of predicted forced expiratory volume in one second (FEV1\%), St. George's Respiratory Questionnaire (SGRQ), COPD Assessment Test (CAT), 6-min walk distance test (6MWD), exacerbations, and air trapping. We used generalized linear mixed models to evaluate the association between living in food deserts and respiratory outcomes, adjusting for age, gender, race, education, income, marital status, BMI, smoking status, pack years, and urban status

Results: Among 2713 participants, 22\% lived in food deserts. Participants living in food deserts were less likely to be white and more likely to have a lower income than those who did not live in food deserts. In the adjusted model controlling for demographics and individual income, living in food deserts was associated lower FEV $1 \%(\beta=-2.51$, $P=0.046)$, higher air trapping $(\beta=2.47, P=0.008)$, worse $S G R Q(\beta=3.48, P=0.001)$ and $C A T(\beta=1.20, P=0.003)$ scores, and $56 \%$ greater odds of severe exacerbations $(P=0.004)$. Results were consistent when looking at food access alone, regardless of whether participants lived in low income areas.
\end{abstract}

Conclusions: Findings suggest an independent association between food desert and food access alone with COPD outcomes. Health program planning may benefit from addressing disparities in access to food.

Keywords: Food, Access, Food desert, Disparities, COPD, Respiratory

\footnotetext{
${ }^{*}$ Correspondence: emougha2@jhmi.edu

1 Department of Medicine, Johns Hopkins University, 4940 Eastern

Avenue, Baltimore, MD 21224, USA

Full list of author information is available at the end of the article
}

\begin{abstract}
Introduction
Chronic obstructive pulmonary disease (COPD) is a leading cause of morbidity and mortality in the United States (U.S.) and the world, with almost $6 \%$ of the population in the United States having COPD [1-3]. Epidemiologic studies have highlighted socioeconomic and environmental factors as major contributors to COPD prevalence
\end{abstract}


and adverse health outcomes [4-9]. Poor dietary intake has been attributed to worse COPD outcomes $[10,11]$. Further, several studies have investigated the association of food deserts, defined as underserved areas that lack access to affordable healthy foods, with health outcomes [12-16]; however, the association between food desert and COPD has not yet been established. Further, it is empirically difficult to distinguish whether these associations are due to low socioeconomic status (SES) factors or low food access; that is, areas where more than onethird of the population have limited access to the nearest supermarket [12-16]. Meaningful differences in food access exist in neighborhoods with similar SES, such that low food access is not strictly found in low income areas, but rather both low and high food access areas exist within high and low SES neighborhoods $[17,18]$, and the effect of food access alone on health has been studied seldom, with mixed results [19-23]. No currently published studies have investigated the association between food desert, nor low food access areas, and COPD outcomes.

Given the importance of diet on COPD outcomes and lack of studies investigating the association between food desert and COPD, the present work links a nationallyavailable food access dataset to the SPIROMICS Air (SubPopulations and InteRmediate Outcome Measures in COPD Study) dataset to evaluate the association of living in food desert and low food access areas on COPDrelated respiratory outcomes, and further investigate whether these associations differ by neighborhood poverty or urban-rural status. We hypothesize that living in a food desert area, and in particular living in an area with low food access, is associated with worse COPD outcomes.

\section{Methods}

The SPIROMICS study is a multicenter study that includes current and former smokers ( $\geq 20$ pack years) with or without airflow obstruction and healthy participants who were non-smokers aged 40 to 80 years recruited from 12 clinical sites spread across the United States. Only participants who were current or former smokers were analyzed here [24]. Particpants who were missing 2010 census geographic identifiers, food desert data, or who did not consent for geocoding, were excluded (Additional file 2: Appendix Figure E1). The Institutional Review Board of Columbia University, Johns Hopkins University, Wake Forest University, University of Utah, University of Michigan, University of California at Los Angeles, University of California at San Francisco, University of North Carolina at Chapel Hill, National Jewish Health, University of Illioins at Chicago, University of Alabama, Temple University and University of Iowa along with all other institutions that were participating in SPIROMICS approved the study protocols and granted ethical approval. Informed consent was obtained from all subjects.

\section{Assessment of food desert and food access}

As part of SPIROMICS AIR [25], an ancillary study to SPIROMICS with the goal of understanding the effects of air pollutants on COPD outcomes, census tract data of participants' residential addresses was linked to the Food Access Research Atlas (FARA), a web-based mapping tool from the United States Department of Agriculture's Economic Research Service [12]. The food desert data was from year 2010; SPIROMICS AIR data was collected between 2010 and 2015. Food desert was defined as an area of low income and low food access [12]. Low food access area was defined as an area where at least a third of people live more than 0.5 miles in urban areas or more than 10 miles in rural areas from the nearest supermarket, supercenter or large grocery stores [12], an approach utilized in several other research studies [19-21, 26-29]. Low income area was defined as an area where the poverty rate is 20 percent or greater, or the area's median family income is less than or equal to $80 \%$ of the statewide median family income, or is in a metropolitan area and has a median family income less than or equal to $80 \%$ of the metropolitan area's median family income [12].

\section{Outcomes}

COPD related outcomes included baseline percentage of predicted forced expiratory volume in one second ( $\mathrm{FEV}_{1} \%$ predicted) [30], respiratory health-related quality of life using the St. George's Respiratory Questionnaire (SGRQ) [31], COPD health status using COPD Assessment Test (CAT) scores [32], dyspnea using modified Medical Research Council (mMRC) dyspnea scale [33], exercise capacity using the 6-min walk distance test (6MWD) [34], and exacerbations (moderate and severe, where moderate exacerbations were defined as worsening respiratory symptoms requiring additional medication and an urgent care or unscheduled physician visit, and severe exacerbations were defined as worsening respiratory symptoms requiring hospitalization or an emergency department visit) in the last 12 months. Airway structure using CT- related outcomes included total \% emphysema, and air trapping defined as the percentage of lung voxels in the field below -856 Hounsfield units at residual volume [35].

\section{Covariates}

Covariates include age, gender, self reported race (white vs. non-white), education (some college or above vs. less than some college), income (under $\$ 15,000, \$ 15,000$ $\$ 34,999, \$ 35,000-49,999, \$ 50,000-74,999$, above $\$ 75,000$, 
declines to answer/missing), marital status (married vs. not married), BMI (continuous), smoking status (current smokers vs. former smokers), pack years, and urban status (urban vs. rural, where urban and rural status was defined at the census tract level for each participant based on established criteria from the U.S Census Bureau, which classifies each census tract as either urban or rural depending on population density) [36]. In addition, a categorical variable for clinical sites was included as a covariate.

Other covariates for the food access results included neighborhood poverty, a dichotomous variable, indicating low income tract vs. non-low income tract, merged directly from Food Access Research Atlas (FARA) [12]. This variable, along with food access, constitute the official definition of food desert as stated previously.

\section{Statistical analysis}

Descriptive analysis was performed of all variables using summary statistics, histograms and scatter plots. Participant characteristics were compared for those who are residing in food deserts versus non-food deserts as well as low food access versus non-low food access, and their differences were tested using t-tests and chi-squared tests. To assess differences in COPD-related outcomes across food deserts and low food access areas, cross-sectional linear and logistic regression was performed for each continuous and dichotomous COPD outcome on food desert or food access adjusting for covariates. We tested for multicollinearity by computing variance inflation factor (VIF), and all predictors had VIF $<4$ across different models. As a sensitivity analysis, the models were run adjusting for FEV1\% predicted; and as secondary analyses, to determine whether differences in food desert or access on respiratory outcomes differed by COPD status, interaction terms were tested and stratified models by COPD status were conducted.

Based on a priori hypotheses, the effect modification by urban status and neighborhood poverty on food access's association with COPD-outcomes was examined. A multiplicative interaction term between food access and either urban status or neighborhood poverty was included, adjusting for the remaining covariates. Direction and statistical significance of interaction was assessed. The effect estimates of food access within urban and rural or low income and non-low income tracts were also separately estimated using stratified analysis. The effect modification by urban status on food desert was not tested because of the limited sample size $(n=10)$ for participants residing in rural areas that were food deserts.

All statistical analyses were performed using STATA version 15.1. The threshold of $P<0.05$ was used for statistical significance for main and interaction effects.

\section{Results}

\section{Participant characteristics}

Current or former smokers $(n=2713)$ (Table 1) were included and they were $46 \%$ female, $77 \%$ white with a mean age of 63.5 . The majority of participants (56\%) had at least some college education and half $(52 \%)$ had an annual income under $\$ 50,000$. Almost a quarter $(22.2 \%)$ of participants resided in food desert areas and were less likely to be white or married; and more likely to be female, have lower educational attainment and an income under $\$ 15,000$ compared to those that do not reside in food deserts (Table 1). In addition, participants residing

Table 1 Participant characteristics

\begin{tabular}{|c|c|c|c|}
\hline & $\begin{array}{l}\text { Food desert }^{a} \\
(N=604)\end{array}$ & $\begin{array}{l}\text { Non-food } \\
\text { desert }^{\mathrm{a}} \\
(\mathrm{N}=2109)\end{array}$ & $p$ Value \\
\hline $\begin{array}{l}\text { FEV1\% pred., } \\
\text { mean } \pm \text { SD }\end{array}$ & $71.7 \pm 27.2$ & $73.4 \pm 26.3$ & 0.159 \\
\hline $\begin{array}{l}\text { COPD (Strata 3 \& } \\
4)^{b}, \%\end{array}$ & 64.2 & 66.9 & 0.230 \\
\hline Age, mean $\pm S D$ & $60.6 \pm 8.8$ & $64.3 \pm 8.8$ & $<0.001$ \\
\hline Female, $\%$ & 50.2 & 44.9 & 0.021 \\
\hline White, \% & 61.8 & 80.9 & $<0.001$ \\
\hline $\begin{array}{l}\text { Some college or } \\
\text { above, } \%\end{array}$ & 44.9 & 59.4 & $<0.001$ \\
\hline Income, \% & & & $<0.001$ \\
\hline Under $\$ 15,000, \%$ & 30.8 & 17.2 & \\
\hline$\$ 15,000-\$ 34,999, \%$ & 24.0 & 17.7 & \\
\hline$\$ 35,000-\$ 49,999, \%$ & 11.5 & 12.7 & \\
\hline$\$ 50,000-\$ 74,999, \%$ & 11.8 & 15.0 & \\
\hline$>\$ 75,000, \%$ & 8.0 & 19.5 & \\
\hline Decline to answer, \% & 13.8 & 18.0 & \\
\hline Married, \% & 35.6 & 50.0 & $<0.001$ \\
\hline Nonrural, \% & 98.3 & 86.2 & $<0.001$ \\
\hline $\mathrm{BMI}, \%$ & $28.3 \pm 5.6$ & $27.8 \pm 5.2$ & 0.064 \\
\hline Currently Smoking, \% & 54.1 & 36.0 & $<0.001$ \\
\hline Pack years, mean $\pm S D$ & $47.6 \pm 32.8$ & $49.8 \pm 25.0$ & 0.082 \\
\hline Low income tract, \% & 100.0 & 23.1 & $<0.001$ \\
\hline Low food access, \% & 100.0 & 55.5 & $<0.001$ \\
\hline
\end{tabular}

Data are given as percentages unless otherwise indicated

Bold values indicate statistical significance at the $p<0.05$ level

${ }^{a}$ Food desert refers to areas defined as both low food access and low income tracts. Low food access refers to a census tract with at least 500 people or 33 percent of the population living more than $1 / 2$ mile (urban areas) or 10 miles (rural areas) from the nearest supermarket, supercenter, or large grocery store. Low income tract refers to a census tract where the tract's poverty rate is 20 percent or greater, or the tract's median family income is less than or equal to $80 \%$ of the State-wide median family income, or the tract is in a metropolitan area and has a median family income less than or equal to 80 percent of the metropolitan area's median family income

${ }^{\mathrm{b}}$ Stratum 3 includes participants with $>20$ pack-years and mild/moderate COPD with $\mathrm{FEV}_{1} / \mathrm{FVC}<0.7$ and $\mathrm{FEV} 1>50 \%$ predicted (GOLD stage 1 and 2 ) measured during enrollment. Stratum 4 includes participants with $>20$ pack-years and severe COPD with $\mathrm{FEV}_{1} / \mathrm{FVC}<0.7$ and $\mathrm{FEV}_{1}<50 \%$ predicted (GOLD stage 3 and 4) measured during enrollment [24] 
in food desert areas were more likely to be current smokers compared to those who do not live in food desert areas. Of the participants living in food deserts $64 \%$ had COPD, and of those who did not live in food deserts $67 \%$ had COPD. (Table 1).

There were an additional 1171 participants who also lived in low food access areas, but not in poverty areas. Those residing in low food access areas were more likely to be white, married, have a higher educational attainment and individual income, and more likely to be residing in urban areas than those residing in non-low food access areas (Additional file 3: Appendix Table E1).

\section{Multivariable regression}

\section{Association of food deserts and COPD-outcomes}

In minimal adjusted analyses adjusting only for study site, residing in food deserts was associated with worse quality of life and respiratory symptoms including worse CAT score, SGRQ score, shorter 6-MWD, and greater odds of exacerbations and mean \% emphysema than those not residing in food desert areas (Table 2). In fully adjusted models controlling for demographics and individual SES, living in food deserts continued to be associated with several measures of COPD morbidity. Specifically, residing in a food desert was associated with 3.5 points higher SGRQ $(\beta=3.48, P=0.001)$ and CAT $(\beta=1.20$, $P=0.003)$ scores, and a shorter $6 \mathrm{MWD}(\beta=-12.7$, $P=0.025)$. Additionally living in a food desert was associated with objective measures, including lower FEV1\% predicted $(\beta=-2.51, P=0.046)$ and higher air trapping ( $\beta=2.47, P=0.008)$ on $\mathrm{CT}$ imaging. Furthermore, participants residing in food deserts had $36 \%$ greater odds of any exacerbation $(\mathrm{OR}=1.36, P=0.010)$ and $56 \%$ greater odds of severe exacerbations $(\mathrm{OR}=1.56, P=0.004)$ in the prior 12 months than did those not living in food deserts (Table 2).

In sensitivity analyses, inclusion of FEV1\% predicted as a covariate attenuated some of the associations between food desert and COPD-outcomes (Additional file 1: Appendix Table E2). Adjusting for the confounders along with FEV1\% predicted, food desert remained statistically significantly associated with worse CAT, SGRQ and increased severe exacerbation risk. In addition, there was no statistically significant interaction by COPD status; but for those outcomes for which the interaction approached nominal significance (e.g., 6MWD, odds of any exacerbation), the direction of interaction was such that adverse associations between food desert and outcomes were generally more adverse for the participants with COPD (vs. without COPD) (Additional file 1: Appendix Table E3).

\section{Association of food access and COPD-outcomes}

In order to understand whether the associations between food desert and COPD outcomes are driven by low food access or neighborhood poverty, we separately explored whether low food access alone was associated with COPD outcomes. There was generally no evidence

Table 2 Differences $(95 \% \mathrm{Cl}$ ) in COPD-related outcomes for former and current smokers in study population residing in food desert areas versus non-food desert areas

\begin{tabular}{|c|c|c|c|c|c|c|}
\hline & \multicolumn{3}{|c|}{ Minimally adjusted $^{a}$} & \multicolumn{3}{|c|}{ Adjusted $^{\mathrm{b}}$} \\
\hline & \multicolumn{2}{|c|}{$\begin{array}{l}\text { Mean difference or odds ratio (95\% } \\
\mathrm{Cl})\end{array}$} & \multirow[t]{2}{*}{$P$ value } & \multicolumn{2}{|c|}{$\begin{array}{l}\text { Mean difference or odds ratio (95\% } \\
\mathrm{Cl})\end{array}$} & \multirow[t]{2}{*}{$\begin{array}{l}P \\
\text { value }\end{array}$} \\
\hline \multicolumn{5}{|l|}{ Lung function } & & \\
\hline FEV\%Pred & -0.27 & $(-2.70,2.16)$ & 0.828 & -2.51 & $(-4.97,-0.05)$ & 0.046 \\
\hline $\operatorname{COPD}(\mathrm{OR})^{\mathrm{c}}$ & 0.91 & $(0.74,1.11)$ & 0.333 & 1.20 & $(0.96,1.50)$ & 0.112 \\
\hline \multicolumn{7}{|c|}{ Quality of life/respiratory symptoms } \\
\hline CAT & 2.38 & $(1.58,3.18)$ & $<0.001$ & 1.20 & $(0.40,2.00)$ & 0.003 \\
\hline $\mathrm{mMRC}$ & 0.13 & $(0.03,0.22)$ & 0.012 & 0.06 & $(-0.04,0.16)$ & 0.210 \\
\hline SGRQ total & 5.70 & $(3.71,7.70)$ & $<0.001$ & 3.48 & $(1.49,5.47)$ & 0.001 \\
\hline 6-min walk distance (meters) & -16.0 & $(-27.3,-4.73)$ & 0.005 & -12.7 & $(-23.9,-1.58)$ & 0.025 \\
\hline \multicolumn{7}{|l|}{ Chest CT metric } \\
\hline \% emphysema $(-950)$ & -1.09 & $(-2.07,-0.12)$ & 0.028 & 0.30 & $(-0.58,1.18)$ & 0.508 \\
\hline$\%$ air trapping $(-856)$ & -1.39 & $(-3.46,0.68)$ & 0.187 & 2.47 & $(0.65,4.29)$ & 0.008 \\
\hline \multicolumn{7}{|l|}{ Exacerbations, last 12 months } \\
\hline Any $(\mathrm{OR})^{\mathrm{c}}$ & 1.42 & $(1.14,1.76)$ & 0.002 & 1.36 & $(1.08,1.72)$ & 0.010 \\
\hline Severe $(O R)^{c}$ & 1.70 & $(1.27,2.26)$ & $<0.001$ & 1.56 & $(1.15,2.13)$ & 0.004 \\
\hline
\end{tabular}

Bold values indicate statistical significance at the $p<0.05$ level

${ }^{\text {a }}$ Adjusted by clinical centers

${ }^{\mathrm{b}}$ Adjusted for clinical centers, age, sex, race, education, income, marital status, rural status, BMI, smoking status, and pack years

${ }^{\mathrm{c}}$ Coefficient represents odds ratio 
of effect modification by neighborhood poverty on the associations between food access and COPD-outcomes except for CAT ( $ß i n t x=1.38, P=0.042)$ and any exacerbation (ORintx $=1.70, P=0.001)$, both of which suggested more adverse association with low food access in low income tracts than in non-low income tracts. But, in stratified analysis, food access was not associated with either CAT or any exacerbations across low and non-low income tracts [difference in CAT score $0.89, P=0.23$ in low income areas and $0.25, P=0.59$ in non-low income areas; odds ratio of any exacerbation was $1.27, P=0.22$ in low income areas and 1.01, $P=0.94$ in non-low income areas].

For the remaining outcomes, there was no significant interaction between food access and neighborhood poverty. In models adjusted for demographics, individual SES and neighborhood poverty, residing in a low food access area was associated with higher odds of COPD, lower lung function, and higher emphysema and gas trapping. In addition, low food access was associated with higher dyspnea (mMRC: $\beta=0.10, P=0.030$ ), and worse quality of life (SGRQ: $\beta=3.30, P<0.001$ ). Furthermore, participants residing in a low food access area had $52 \%$ greater odds of severe exacerbation $(\mathrm{OR}=1.52$, $P=0.012$ ) than did those who did not live in a low food access area (Table 3 ).

\section{Association of food access and COPD-outcomes by urban/ rural status}

Though almost all subjects residing in food deserts were living in urban areas preventing evaluation of urban / rural differences, 73 participants $(4.7 \%)$ of those living in low food access areas were also living in rural areas. There was evidence of effect modification by urban / rural status on the associations between food access and COPDoutcomes (Additional file 3: Appendix Figure E2). For all but the exacerbation outcomes, the interaction effect estimates were statistically significant, and the direction of interaction was such that adverse associations between residing in low food access areas and COPD-outcomes were consistently greater if the participants resided in urban areas than in rural areas. For those residing in urban areas, low food access was adversely associated with nearly all COPD-outcomes considered (Table 4). Specifically, urban low food access was associated with a worse FEV1\% predicted $(\beta=-5.25, P<0.001)$, greater odds of COPD $(\mathrm{OR}=1.52, P=0.001)$, worse dyspnea (mMRC: $\beta=0.16, P=0.002)$, worse CAT $(\beta=1.05$, $P=0.009)$ worse SGRQ total score $(\beta=4.28, P<0.001)$ and greater odds of exacerbation $(\mathrm{OR}=1.35, P=0.028)$ and severe exacerbations ( $\mathrm{OR}=1.62, P=0.011)$. CT scan findings were also significantly worse with a higher percent emphysema $(\beta=1.54, P=0.002)$ and higher percent
Table 3 Differences (95\% Cl) in COPD-related outcomes for former and current smokers in study population residing in low food access areas versus non-low food access areas

\begin{tabular}{llll}
\hline & \multicolumn{2}{l}{ Adjusted $^{\mathbf{a}}$} \\
\cline { 2 - 4 } & $\begin{array}{l}\text { Mean difference or odds } \\
\text { ratio }(\mathbf{9 5 \%} \mathrm{Cl})\end{array}$ & P value \\
\hline $\begin{array}{llll}\text { Lung function } \\
\text { FEV\%Pred }\end{array}$ & -4.40 & $(-6.78,-2.03)$ & $<\mathbf{0 . 0 0 1}$ \\
COPD (odds ratio) & & & \\
Quality of life/respiratory symptoms & 1.42 & $(1.13,1.78)$ & $\mathbf{0 . 0 0 2}$ \\
CAT & 0.70 & $(-0.03,1.43)$ & 0.060 \\
mMRC & 0.10 & $(0.01,0.20)$ & $\mathbf{0 . 0 3 0}$ \\
SGRQ total & 3.30 & $(1.52,5.10)$ & $<\mathbf{0 . 0 0 1}$ \\
6-min walk distance (meters) & -3.03 & $(-13.7,7.59)$ & 0.576 \\
Chest CT metric & & & \\
\% Emphysema (-950) & 1.22 & $(0.33,2.12)$ & $\mathbf{0 . 0 0 7}$ \\
\% air trapping $(-856)$ & 3.23 & $(1.45,5.01)$ & $<\mathbf{0 . 0 0 1}$ \\
Exacerbations, last 12 months & & & \\
Any (OR) & 1.24 & $(0.98,1.58)$ & 0.072 \\
Severe (OR) & 1.52 & $(1.10,2.10)$ & $\mathbf{0 . 0 1 2}$ \\
\hline
\end{tabular}

Bold values indicate statistical significance at the $p<0.05$ level

${ }^{a}$ Adjusted for neighborhood poverty, clinical centers, age, sex, race, education, income, marital status, rural status, BMI, smoking status, and pack years

${ }^{\mathrm{b}}$ Coefficient represents odds ratio

air trapping $(\beta=4.04, P<0.001)$. The magnitudes of associations between low food access and COPD-outcome were consistently larger among those who resided in urban areas than for all participants.

\section{Discussion}

To our knowledge, there have been no previous studies investigating the association of food deserts and the impact of low food access on COPD outcomes. The main findings of our study are three-fold. First, living in a food desert area was independently associated with worse COPD outcomes. Another key finding was the consistency in our results with food access alone, regardless of neighborhood SES, suggesting that limited food access is detrimental in both low and high income neighborhoods. Additionally, the connections between low food access and COPD outcomes were stronger in urban areas compared with rural areas.

There is increasing recognition that the neighborhood environment can impact chronic disease risk and outcomes [37-39]. In fact, studies have shown that living in food deserts has been associated with adverse outcomes focusing on obesity, diabetes and heart diseases [19-22, $40,41]$. In this current study, we show that living in a food desert area is also associated with several worse COPD outcomes, including lower lung function, higher 
Table 4 Differences $(95 \% \mathrm{Cl})$ in COPD-related outcomes for former and current smokers in study population residing in low food access areas versus non-low food access areas by urban status

\begin{tabular}{|c|c|c|c|c|c|c|}
\hline & \multicolumn{3}{|l|}{ Rural $(\mathrm{N}=302)$} & \multicolumn{3}{|l|}{ Urban $(N=2411)$} \\
\hline & $\begin{array}{l}\text { Mean difference or } \\
\text { odds ratio }(95 \% \mathrm{Cl})\end{array}$ & & $P$ value & $\begin{array}{l}\text { Mean difference or } \\
\text { odds ratio }(95 \% \mathrm{Cl})\end{array}$ & & $P$ value \\
\hline \multicolumn{7}{|l|}{ Lung function } \\
\hline FEV\%Pred & 2.38 & $(-3.75,8.51)$ & 0.445 & -5.25 & $(-7.84,-2.66)$ & $<0.001$ \\
\hline $\operatorname{COPD}(\mathrm{OR})^{\mathrm{a}}$ & 0.77 & $(0.41,1.44)$ & 0.415 & 1.52 & $(1.20,1.94)$ & $<0.001$ \\
\hline \multicolumn{7}{|c|}{ Quality of life/respiratory symptoms } \\
\hline CAT & -1.66 & $(-3.60,0.29)$ & 0.094 & 1.05 & $(0.26,1.84)$ & 0.009 \\
\hline $\mathrm{mMRC}$ & -0.24 & $(-0.50,0.02)$ & 0.070 & 0.16 & $(0.06,0.26)$ & 0.002 \\
\hline SGRQ total & -3.96 & $(-8.69,0.78)$ & 0.101 & 4.28 & $(2.36,6.20)$ & $<0.001$ \\
\hline 6-min walk Distance (meters) & 31.5 & $(5.13,57.8)$ & 0.019 & -8.93 & $(-20.5,2.68)$ & 0.132 \\
\hline \multicolumn{7}{|l|}{ Chest CT metric } \\
\hline \% Emphysema (-950) & -0.99 & $(-3.19,1.21)$ & 0.377 & 1.54 & $(0.55,2.52)$ & 0.002 \\
\hline$\%$ air trapping $(-856)$ & -1.35 & $(-6.30,3.59)$ & 0.591 & 4.04 & $(2.11,5.97)$ & $<0.001$ \\
\hline \multicolumn{7}{|l|}{ Exacerbations, last 12 months } \\
\hline Any (odds ratio) ${ }^{a}$ & 0.70 & $(0.37,1.33)$ & 0.275 & 1.35 & $(1.03,1.76)$ & 0.028 \\
\hline Severe (odds ratio) ${ }^{\mathrm{a}}$ & 0.80 & $(0.29,2.17)$ & 0.661 & 1.62 & $(1.12,2.34)$ & 0.011 \\
\hline
\end{tabular}

All modes were adjusted for clinical centers, age, sex, race, education, income, marital status, BMI, smoking status, and pack years

Bold values indicate statistical significance at the $p<0.05$ level

${ }^{\text {a }}$ Coefficient represents odds ratio

odds of COPD exacerbations, and worse quality of life and $\mathrm{CT}$ evidence of gas trapping, even after adjusting for smoking status and individual income. Food desert is a composite measure of low food access and neighborhood poverty [12]. Low individual SES has been a recognized risk factor for poor COPD outcomes [42] and additional evidence is suggesting that neighborhood SES is also associated with worse outcomes [37-39]. Other factors imbedded within the neighborhood SES, such as higher air pollutant exposures, may also have a variety of influences on respiratory morbidity that could further explain our findings [38, 39].

When looking at food access alone, only a few studies have reported the association between availability of food stores and outcomes in chronic health conditions $[20,21,37,38]$. Though results have been inconsistent, it has been demonstrated that the availability of supermarkets plays an important role in diet quality, is positively associated with a healthier food choice [40, 43-45], and is associated with lower prevalence of obesity and overweight [40]. Importantly, there are several studies suggesting that a healthier diet leads to better COPD outcomes $[46,47]$ perhaps by protecting the lungs from oxidative damage $[47,48]$. For example, higher fruit and vegetable consumption and a lower intake of dairy products, red meats, sweets, and sugary drinks have been linked to lower prevalence of COPD, higher FEV1\% predicted, and lower mortality in individuals with COPD;
$[46,47,49,50]$ and omega 3 intake has been associated with improved COPD outcomes [51]. Therefore, it is reasonable to consider that access to local healthy foods may influence COPD respiratory outcomes [52]. In fact our results were consistent with these findings, demonstrating that when looking at food access alone, living in low food access areas was associated with worse COPD outcomes, specifically worse FEV1\% predicted, a higher odds of COPD, worse CT imaging metrics including higher percent emphysema and air trapping and more severe COPD exacerbations. Further, the effect on COPD outcomes was largely similar whether individuals resided in a low SES neighborhood or a more affluent neighborhood. Only the association of low food access with CAT score and any exacerbation risk, was increased in areas that were also high poverty compared to lower poverty areas.

The results further suggest that the impact of low food access may be greatest in urban areas. Our results could be explained by the ubiquitous prevalence of unhealthy options (e.g., corner stores, fast food chains, etc.) in cities compared with rural areas [29], and in this type of urban setting, people will be more inclined to go to a fast food restaurant or corner store that is much closer and cheaper rather than walking farther away to a healthy food source [53-55]. As an example, a study in Austin, Texas, showed that there are three times more unhealthy food stores than healthy ones that are within walking 
distance in the city proper [29]. Additionally, people living in urban areas tend to pay significantly more, an estimated 3-37\% more, than those who live in non-urban areas to purchase the same healthy groceries $[56,57]$. This may further discourage the urban community from purchasing healthy options, thus leading to worse COPD outcomes.

The study has several limitations. First, though we looked at the association of both food desert and food access adjusting for neighborhood poverty, there are additional neighborhood factors such as availability of pharmacy or health care that may track with food deserts and low food access and be confounding factors associated with worse COPD morbidity. Second, there are additional factors that contribute to healthy food choices in addition to access to healthy foods such as vehicle availability and personal choice [58]. This additional information was not available, nor was information on actual dietary intake, though the finding that low food access is associated with adverse outcomes in both lower and higher SES neighborhoods suggests that dietary factors may be playing a role. Further, the findings suggest a potential mediatory role of lung function in the relationship between food desert and COPD-outcomes. In addition, only a small number of participants lived in a rural low food access setting compared with urban areas. This restricts the power to identify an association between food access and COPD outcomes in rural areas. Given the high prevalence of COPD and high COPD morbidity in rural areas, the role of food desert and other contextual factors that may drive COPD morbidity in rural areas deserves further attention [59]. Also, our participants were all current or former smokers, thus we are unable to draw conclusions regarding association of residing in food desert or low food access areas with COPD outcomes among never smokers. Finally, the cross-sectional study design makes it difficult to explicitly infer causal links between food access and COPD outcomes.

In conclusion, in this multicenter study, we have demonstrated an independent association between food desert and worse COPD-related outcomes, but also the independent effect of food access alone on COPD outcomes, emphasizing the importance that diet and access to healthy food choices may have on respiratory morbidity. Associations persisted across varying degrees of individual- and contextual-level (i.e., neighborhood) factors supporting that low food access is problematic regardless of neighborhood income. Low food access results were more pronounced in urban compared to rural environments. Such insight warrants a further investigation of how COPD-related outcomes are impacted by the proximity to food access. Further, food access should be considered for utilization in novel and equitable health strategies in policy implications for local municipalities, in addition to current COPD-related clinical guidelines.

\section{Abbreviations}

COPD: Chronic obstructive pulmonary disease; SPIROMICS: SubPopulations and intermediate outcome measures in COPD study; FEV1\%: Percentage of predicted forced expiratory volume in one second; SGRQ: St. George's Respiratory Questionnaire; CAT: COPD assessment test; 6MWD: 6-min walk distance test; mMRC: Modified medical research council; FARA: Food access research atlas.

\section{Supplementary information}

The online version contains supplementary material available at https://doi. org/10.1186/s12890-021-01485-8.

Additional file 1. Additional patient characteristics and differences tables. Additional file 2. Participant flow chart.

Additional file 3. Urban/rural status and food access interaction.

\section{Acknowledgements}

SPIROMICS Acknowledgement and Funding Statement: More information about the study and how to access SPIROMICS data is available at wWw.spiro mics.org. The authors would like to acknowledge the University of North Carolina at Chapel Hill BioSpecimen Processing Facility for sample processing, storage, and sample disbursements (http://bsp.web.unc.edu/). We would like to acknowledge the following current and former investigators of the SPIROMICS sites and reading centers: Neil E Alexis, MD; Wayne H Anderson, PhD; Mehrdad Arjomandi, MD; Igor Barjaktarevic, MD, PhD; R Graham Barr, MD, DrPH; Patricia Basta, PhD; Lori A Bateman, MSc; Surya P Bhatt, MD; Eugene R Bleecker, MD; Richard C Boucher, MD; Russell P Bowler, MD, PhD; Stephanie A Christenson, MD; Alejandro P Comellas, MD; Christopher B Cooper, MD, PhD; David J Couper, PhD; Gerard J Criner, MD; Ronald G Crystal, MD; Jeffrey L Curtis, MD; Claire M Doerschuk, MD; MarkT Dransfield, MD; Brad Drummond, MD; Christine M Freeman, PhD; Craig Galban, PhD; MeiLan K Han, MD, MS; Nadia N Hansel, MD, MPH; Annette T Hastie, PhD; Eric A Hoffman, PhD; Yvonne Huang, MD; Robert J Kaner, MD; Richard E Kanner, MD; Eric C Kleerup, MD; Jerry A Krishnan, MD, PhD; Lisa M LaVange, PhD; Stephen C Lazarus, MD; Fernando J Martinez, MD, MS; Deborah A Meyers, PhD; Wendy C Moore, MD; John D Newell Jr, MD; Robert Paine, III, MD; Laura Paulin, MD, MHS; Stephen P Peters, MD, PhD; Cheryl Pirozzi, MD; Nirupama Putcha, MD, MHS; Elizabeth C Oelsner, MD, MPH; Wanda K O’Neal, PhD; Victor E Ortega, MD, PhD; Sanjeev Raman, MBBS, MD; Stephen I. Rennard, MD; Donald P Tashkin, MD; J Michael Wells, MD; Robert A Wise, MD; and Prescott G Woodruff, MD, MPH. The project officers from the Lung Division of the National Heart, Lung, and Blood Institute were Lisa Postow, PhD, and Lisa Viviano, BSN.

\section{Authors' contributions}

The authors' responsibilities were as follow: EM helped develop research question, contributed to data collection and prepared first draft of the manuscript. NHN developed research question provided guidance on data interpretation and analysis and had primary responsibility for final content, HW conducted statistical analysis, and prepared the first draft of the manuscript; PG, KRR, SR, $V T$ contributed to study design, and reviewed and edited the manuscript. EAH, APC, VEO, TP, JAK, MBD, DC, RGB, RP, JDK, LMP, NP, NHN, contributed to SPIROMICS study design, data collection and reviewed and edited the manuscript. All authors have read and approved the final manuscript, agreed to be cited as co-authors and accepted the order of authorship.

\section{Funding}

SPIROMICS Air was supported by grant 5R01ES023500. SPIROMICS was supported by contracts from the NIH/NHLBI (HHSN268200900013C, HHSN268200900014C, HHSN268200900015C, HHSN268200900016C, HHSN268200900017C, HHSN268200900018C, HHSN268200900019C, HHSN268200900020C), grants from the NIH/NHLBI (H), and supplemented 
by contributions made through the Foundation for the $\mathrm{NIH}$ and the COPD Foundation. Please see full list in acknowledgments.

\section{Availability of data and materials}

The data that support the findings of this study are available from SPIROMICS but restrictions apply to the availability of these data, which were used under license for the current study, and so are not publicly available. Data are however available from the authors upon reasonable request and with permission of SPIROMICS. The datasets on food access generated and analysed during the current study are available in the Food Access Research Atlas repository, https://www.ers.usda.gov/data-products/food-access-research-atlas.aspx

\section{Declarations}

\section{Ethics approval and consent to participate}

The institutional review boards of all institutions that were participating in SPIROMICS approved the study protocols and granted ethical approval. All methods were carried out in accordance with relevant guidelines and regulations. Informed consent was obtained from all subjects.

\section{Consent for Publication}

Not applicable.

\section{Competing interests}

The authors declare that they have no competing interests. R. G. Buhr received personal consulting fees from GlaxoSmithKline and Mylan/Theravance Biopharma, unrelated to this submission.

\section{Author details}

${ }^{1}$ Department of Medicine, Johns Hopkins University, 4940 Eastern Avenue, Baltimore, MD 21224, USA. ${ }^{2}$ Division of Pulmonary and Critical Care, Johns Hopkins University, 4940 Eastern Avenue, Baltimore, MD 21224, USA. ${ }^{3}$ Department of Internal Medicine, University of lowa, lowa City, IA, USA. ${ }^{4}$ Department of Medicine, Wake Forest School of Medicine, Winston Salem, NC, USA. ${ }^{5}$ Department of Medicine, University of Alabama, Birmingham, AL, USA. ${ }^{6}$ Department of Medicine, University of Illinois, Chicago, IL, USA. ${ }^{7}$ Department of Medicine, University of North Carolina At Chapel Hill, Chapel Hill, NC, USA. ${ }^{8}$ Department of Biostatistics, University of North Carolina At Chapel Hill, Chapel Hill, NC, USA. ${ }^{9}$ Department of Medicine, Greater Los Angeles Veterans Affairs Healthcare System, Los Angeles, CA, USA. ${ }^{10}$ Department of Medicine, University of Utah, Salt Lake City, UT, USA. ${ }^{11}$ Department of Medicine and Epidemiology, University of Washington, Seattle, WA, USA. ${ }^{12}$ Department of Medicine, Dartmouth Hitchcock Medical Center, Lebanon, NH, USA.

Received: 11 January 2021 Accepted: 22 March 2021

Published online: 27 April 2021

\section{References}

1. Bkurney P, Jithoo A, Kato B, et al. Chronic obstructive pulmonary disease mortality and prevalence: the associations with smoking and poverty-A bold analysis. Thorax. 2014;69:465-73.

2. Lozano R, Naghavi M, Foreman $\mathrm{K}$, et al. Global and regional mortality from 235 causes of death for 20 age groups in 1990 and 2010: a systematic analysis for the Global Burden of Disease Study 2010. Lancet. 2012;380:2095-128.

3. Heron M, Anderson RN. Changes in the leading cause of death: recent patterns in heart disease and cancer mortality. NCHS Data Brief. 2016;254:1-8

4. Schraufnagel DE, Blasi F, Kraft M, et al. An official American thoracic society and european respiratory society policy statement: disparities in respiratory health. Eur Respir J. 2013;42:906-15.

5. Pleasants RA, Riley IL, Mannino DM. Defining and targeting health disparities in chronic obstructive pulmonary disease. Int J Chron Obstruct Pulmon Dis. 2016;11:2475-96.

6. Adamkiewicz G, Zota AR, Patricia Fabian M, et al. Moving environmental justice indoors: understanding structural influences on residential exposure patterns in low-income communities. Am J Public Health. 2011;101:238-45.
7. Tøttenborg SS, Lange P, Johnsen SP, et al. Socioeconomic inequalities in adherence to inhaled maintenance medications and clinical prognosis of COPD. Respir Med. 2016;119:160-7. https://doi.org/10.1016/J.RMED.2016. 09.007 .

8. Trachtenberg AJ, Dik N, Chateau D, Katz A. Inequities in ambulatory care and the relationship between socioeconomic status and respiratory hospitalizations: a population-based study of a Canadian City. Ann Family Med. 2014;12(5):402-7. https://doi.org/10.1370/afm.1683.

9. Galiatsatos P, Kineza C, Hwang S, et al. Neighbourhood characteristics and health outcomes: evaluating the association between socioeconomic status, tobacco store density and health outcomes in Baltimore City. Tob Control. 2018;27:E19-24.

10. Hanson C, Rutten EP, Wouters EFM, Rennard S. Influence of diet and obesity on COPD development and outcomes. Int J COPD. 2014;9:72333. https://doi.org/10.2147/COPD.S50111.

11. Walda IC, Tabak C, Smit HA. Diet and 20-year chronic obstructive pulmonary disease mortality in middle-aged men from three European countries. Eur J Clin Nutr. 2002;56(7):638-43. https://doi.org/10.1038/sj. ejcn.1601370.

12. Economic Research Service (ERS), U.S. Department of Agriculture (USDA). Food Access Research Atlas, https://www.ers.usda.gov/dataproducts/food-access-research-atlas.aspx.

13. Cummins S, Macintyre S. "Food deserts" —evidence and assumption in health policy making. BMJ. 2002;325:436-8.

14. Diez Roux AV, Christina M. Neighborhoods and health. Ann NY Acad Sci. 2010;1186:125-45.

15. Hendrickson D, Smith C, Eikenberry N. Fruit and vegetable access in four low-income food deserts communities in Minnesota. Agric Hum Values. 2006;23:371-83.

16. Ploeg M ver, Breneman V, Farrigan T, et al. Access to affordable and nutritious food: measuring and understanding food deserts and their consequences. Report to Congress. Usda [Internet]. 2009; 1-150. https://www.ers.usda.gov/webdocs/publications/ap036/12716_ ap036_1_.pdf

17. Powell LM, Slater S, Mirtcheva D, Bao Y, Chaloupka FJ. Food store availability and neighborhood characteristics in the United States. Prev Med. 2007:44:189-95.

18. Liu JL, Han B, Cohen DA. Beyond neighborhood food environments: distance traveled to food establishments in 5 US cities, 2009-2011. Prev Chronic Dis. 2015. https://doi.org/10.5888/pcd12.150065.

19. Kelli HM, Hammadah M, Ahmed H. Association between living in food deserts and cardiovascular risk. Circ Cardiovas Qual Outcomes. 2017;10(9):1-11. https://doi.org/10.1161/CIRCOUTCOMES.116.003532.

20. Kelli HM, Kim JH, Samman Tahhan A. Living in food deserts and adverse cardiovascular outcomes in patients with cardiovascular disease. J Am Heart Assoc. 2019;8(4):e010694. https://doi.org/10.1161/JAHA.118. 010694.

21. Suarez JJ, Isakova T, Anderson CAM, et al. Food access, chronic kidney disease, and hypertension in the US. Am J Prevent Med. 2015;49(6):912-20. https://doi.org/10.1016/j.amepre.2015.07.017.

22. Liese AD, Lamichhane AP, Garzia SCA. Neighborhood characteristics, food deserts, rurality, and type 2 diabetes in youth: Findings from a case-control study. Health Place. 2018;50(February):81-8. https://doi.org/10.1016/j. healthplace.2018.01.004.

23. Chen D, Jaenicke EC, Volpe RJ. Food environments and obesity: household diet expenditure versus food deserts. Am J Public Health. 2016;106(5):881-8. https://doi.org/10.2105/AJPH.2016.303048.

24. Couper D, LaVange LM, Han ML, et al. Design of the subpopulations and intermediate outcomes in copd study (SPIROMICS). Thorax. 2014;69:491-4.

25. Hansel NN, Paulin LM, Gassett AJ, Peng RD, Alexis N, Fan VS, Bleecker E, Bowler R, Comellas AP, Dransfield M, et al. Design of the subpopulations and intermediate outcome measures in COPD (SPIROMICS) AIR study. BMJ Open Respir Res. 2017:4:1-7.

26. Guy CM, David G. Measuring physical access to "healthy foods" in areas of social deprivation: a case study in Car- diff. Int J Consum Stud. 2004;28(3):222-34.

27. Smoyer-Tomic K, Spence J, Amrhein C. Food deserts in the prairies? Supermarket accessibility and neighborhood need in Edmonton Canada. Professional Geogr. 2006;58(3):307-26. 
28. Apparicio P, Cloutier M, Shearmur R. The case of Montreal's missing food deserts: evaluation of accessibility to food supermarkets. Int J Health Geogr. 2007;6:4.

29. Jiao J. Measuring vulnerable population's healthy and unhealthy food access in Austin, Texas. AlMS Public Health. 2016;3(4):722-32. https://doi. org/10.3934/publichealth.2016.4.72.

30. American Thoracic Society. Standardization of spirometry, 1994 update. Am J Respir Crit Care Med. 1995. https://doi.org/10.1164/ajrccm.152.3. 7663792.

31. Jones PW, Quirk FH, Baveystock CM, Littlejohns P. A self-complete measure of health status for chronic airflow limitation. The St. George's Respiratory Questionnaire. Am Rev Respir Dis. 1992;145:1321-7.

32. Jones PW, Harding G, Berry P, et al. Development and first validation of the COPD assessment test. Eur Respir J. 2009;34:648-54.

33. Bestall JC, Paul EA, Garrod R, et al. Usefulness of the Medical Research Council (MRC) dyspnoea scale as a measure of disability in patients with chronic obstructive pulmonary disease. Thorax. 1999;54:581-6.

34. ATS Committee on Proficiency Standards for Clinical Pulmonary Function Laboratories. ATS statement: guidelines for the six-minute walk test. Am J Respir Crit Care Med. 2002;166:111-7. https://doi.org/10.1164/ajrccm. 166.1.at1102.

35. Sieren JP, Newell JD, Barr RG, et al. SPIROMICS protocol for multicenter quantitative computed tomography to phenotype the lungs. Am J Respir Crit Care Med. 2016;194:794-806.

36. US Census Bureau. "Urban and Rural." The United States Census Bureau, 30 Aug. 2018, www.census.gov/programs-surveys/geography/guidance/ geo-areas/urban-rural.html.

37. Sheets $L$, Petroski GF, Jaddoo J, et al. The effect of neighborhood disadvantage on diabetes prevalence. AMIA Annu Symp Proc AMIA Symp. 2017;2017:1547-53.

38. Osman LM, Douglas JG, Garden C, et al. Indoor air quality in homes of patients with chronic obstructive pulmonary disease. Am J Respir Crit Care Med. 2007;176(5):465-72. https://doi.org/10.1164/rccm. 200605-5890C

39. Galiatsatos P, Woo H, Paulin LM, Kind A, et al. The association between neighborhood socioeconomic disadvantage and chronic obstructive pulmonary disease. Int J COPD. 2020;15:981-93.

40. Morland K, Roux AVD, Wing S. Supermarkets other food stores, and obesity the atherosclerosis risk in communities study. Am J Prevent Med. 2006. https://doi.org/10.1016/j.amepre.2005.11.003.

41. Alanna DX, Morris A, Dx X, Kelli M, Dx X. Relation of living in a "food desert "to recurrent hospitalizations in patients with heart failure. Am J Cardiol. 2018;123(2):291-6. https://doi.org/10.1016/j.amjcard.2018.10.004.

42. Prescott $E$, Lange $P$, Vestbo J. Socioeconomic status, lung function and admission to hospital for COPD: results from the Copenhagen City Heart Study. Eur Respir J. 1999;13(5):1109-14. https://doi.org/10.1034/j.13993003.1999.13e28.x (PMID: 10414412).

43. Sorli-Aguilar M, Martin-Lujan F, Flores-Mateo G, et al. RESET Study Group Investigators Dietary patterns are associated with lung function among Spanish smokers without respiratory disease. BMC Pulm Med. 2016;16:162. https://doi.org/10.1186/s12890-016-0326-x.

44. Kaufman JS, Ph D, Jones SJ, Ph D. Proximity of supermarkets is positively associated with diet quality index for pregnancy. Prevent Med. 2004;39:869-75. https://doi.org/10.1016/j.ypmed.2004.03.018.

45. Morland K, Wing S, Diez RA. The contextual effect of the local food environment on residents' diets: the Atherosclerosis Risk in Communities(ARIC) study. Am J Public Health. 2002;92:1761-7.
46. Keranis E, Makris D, Rodopoulou P. Impact of dietary shift to higher-antioxidant foods in COPD: a randomised trial. Eur Respir J. 2010;36(4):77480. https://doi.org/10.1183/09031936.00113809.

47. Franco M, Diez-Roux AV, Nettleton JA. Availability of healthy foods and dietary patterns: the Multi-Ethnic Study of Atherosclerosis Neighborhood characteristics and availability of healthy foods in Baltimore. Am J Clin Nutr. 2009;89(3):897-904. https://doi.org/10.3945/ajcn.2008.26434.Am.

48. Lippman RD. Free radical-induced lipoperoxidation and aging. In: Miquel J, Quintanilha AT, Weber H, eds. Handbook of free radicals and antioxidants in biomedicine. Boca Raton, CRC Press, 1989; pp. 187-197. 27 Tzanakis N, Anagno

49. Keranis E, Makris D, Rodopoulou P, Martinou H, et al. Impact of dietary shift to higher-antioxidant foods in COPD: a randomised trial. Eur Respir J. 2010;36:774-80.

50. Scoditti E, Massaro M, Garbarino S, Toraldo DM. Role of diet in chronic obstructive pulmonary disease prevention and treatment. Nutrients. 2019;11(6):1357. https://doi.org/10.3390/nu11061357.

51. Lemoine SCM, Brigham EP, Woo $\mathrm{H}$, et al. Omega-3 fatty acid intake and prevalent respiratory symptoms among US adults with COPD. BMC Pulm Med. 2019;19:1-9.

52. Larson NI, Story MT, Nelson MC. Neighborhood environments Disparities in access to healthy foods in the US. Am J Prevent Med. 2009;36(1):74-81. https://doi.org/10.1016/j.amepre.2008.09.025.

53. Athens JK, Duncan DT, Elbel B. Proximity to fast-food outlets and supermarkets as predictors of fast-food dining frequency. J Acad Nutr Diet. 2016;1 16(8):1266-75. https://doi.org/10.1016/J.JAND.2015.12.022.

54. He M, Tucker P, Gilliland J, Irwin JD, Larsen K, Hess P. The influence of local food environments on adolescents' food purchasing behaviors. Int J Environ Res Public Health. 2012;9(4):1458-71.

55. Burgoine T, Forouhi NG, Griffin SJ, Wareham NJ, Monsivais P. Associations between exposure to takeaway food outlets, takeaway food consumption, and body weight in Cambridgeshire, UK: Population based, crosssectional study. BMJ. 2014;348:g1464.

56. Morland K, Wing S, Roux AD, Poole C. Neighborhood characteristics associated with the location of food stores and food service places. Am J Prevent Med. 2002;22(1):23-9.

57. Curtis, K. A., Mcclellan, S., Curtis, K. A., \& Mcclellan, S. (2019). American City falling through the safety net: poverty, food assistance and shopping constraints in an American City. Urban Anthropol Stud Cult Syst World Econ Dev, 24(1).

58. Strome S, Johns T, Scicchitano MJ, Shelnutt K. Elements of access: the effects of food outlet proximity, transportation, and realized access on fresh fruit and vegetable consumption in food deserts. Int Q Commun Health Educ. 2016;37(1):61-70. https://doi.org/10.1177/0272684X16 685252.

59. Raju S, Brigham EP, Paulin LM, Putcha N, Balasubramanian A, Hansel NN, McCormack MC. The burden of rural chronic obstructive pulmonary disease: analyses from the National Health and Nutrition Examination survey. Am J Respir Crit Care Med. 2020;201:488-91.

\section{Publisher's Note}

Springer Nature remains neutral with regard to jurisdictional claims in published maps and institutional affiliations.

Ready to submit your research? Choose BMC and benefit from:

- fast, convenient online submission

- thorough peer review by experienced researchers in your field

- rapid publication on acceptance

- support for research data, including large and complex data types

- gold Open Access which fosters wider collaboration and increased citations

- maximum visibility for your research: over $100 \mathrm{M}$ website views per year

At $\mathrm{BMC}$, research is always in progress.

Learn more biomedcentral.com/submissions 